\title{
Derivatized Electrodes in the Electroanalysis of Pyrimethamine/2-Sulfanilamido-3-Methoxypyrazine (Metakelfin) and Lumefantrine/Artemeter (Coartem)
}

\author{
Duke Orata $^{1^{*}}$, Yusuf Amir ${ }^{1}$ and Claire Ninneza ${ }^{2}$ \\ 1. Department of Chemistry, University of Nairobi, Nairobi 30197-00100, Kenya \\ 2. Department of chemistry, University of Bujumbura, Bujumbura, Burundi
}

Received: November 29, 2013 / Accepted: December 18, 2013 / Published: March 25, 2014.

\begin{abstract}
In this paper, the surface of the carbon graphite working electrode has been modified using pyrimethamine/2-sulfanilamido-3-methoxypyrazine (metakelfin) and lumefantrine/artemeter (coartem)-potent antimalarials. The electrochemical profiles of the surface modified electrodes have been studied using cyclic voltammetry. The results indicate that the metakelfin and lumefantrine/artemeter (coartem) have redox active moieties with the oxidation and reduction peaks for pyrimethamine/2-sulfanilamido-3-methoxypyrazine (metakelfin) modified electrode occurring at $0.510 \mathrm{~V}$ and $0.315 \mathrm{~V}$, and that for lumefantrine/artemeter (coartem) occurring at $0.510 \mathrm{~V}$ and $0.300 \mathrm{~V}$. Bentonite, a clay montmorrilonite with octahedral and tetrahedral sites which can undergo isomorphous substitution and other interactions was also used modify the electrode surface. The bentonite modified electrode was then used to study metakelfin and lumefantrine/artemeter (coartem). It was observed that the redox properties of metakelfin and lumefantrine/artemeter (coartem) did not change significantly on the bentonite host matrix. It was observed that the redox activity of artemeter was totally inhibited on the bentonite matrix. Interaction of pyrimethamine/2-sulfanilamido-3-methoxypyrazine (metakelfin) and lumefantrine/artemeter (coartem) modified electrodes with selected biomolecules (methionine, arginine, leucine, tyrosine), isonicotinic acid and acetyl salicyclic acid is also reported.
\end{abstract}

Key words: Surface modified electrodes, cyclic voltammetry, metakelfin, coartem.

\section{Introduction}

Diseases have posed a major challenge to human existence from time immemorial to date. The main diseases which have posed grave danger to the human race include malaria, HIV/Aids, Ebola, etc.. The viral infections have and still pose the greatest challenge. This has forced man to design and synthesize drugs to fight off/treat these conditions. The designed drugs have their properties/characteristics mapped from natural products; a good example being quinine from the Cinchona tree. Unfortunately, with the systematic depletion of fauna and flora which have served as useful data banks for drug information, the scientific

\footnotetext{
*Corresponding author: Duke Orata, Professor, research field: electronically conducting polymers. E-mail: dorata@uonbi.ac.ke; dukeorata@yahoo.com.
}

task of developing new drugs is ever more challenging. The causative agents especially the microbes have also over the period of time mutated in their response to drugs, leading to cases of severe resistance, hence ineffectiveness of the drugs in treatment. An example is the anti-malarial Chloroquine, a drug which was very effectively against malaria in most parts of the world. Today, due to misuse, under-dosage or appearance on the scene of new malaria causing agents, the drug is not very effective against malaria in some individuals $[1,2]$.

Malaria is therefore still a major health threat especially in the tropics. Of the malaria causing parasites (P. malariae, P. ovale, P. falciparum and $P$. vivax) $P$. vivax and $P$. falciparum are the most common, with $P$. falciparum causing the most deadly 
type of malaria infection.

Due to intense research [1-13], new potent anti-malarials have been developed, key in this group is pyrimethamine/2-sulfanilamido-3-methoxypyrazine (metakelfin) and lumefantrine/artemeter (coartem). The drugs have combated the malaria parasite effectively and presently coartem is a first line treatment for malaria in the tropics.

In this paper, the working electrode surface has been chemically modified with pyrimethamine/2-sulfanilamido-3-methoxypyrazine (metakelfin) and lumefantrine/artemeter (coartem). The electrochemical profile of these surface modified electrodes has then been studied using cyclic voltammetry. The results indicate that metakelfin and lumefantrine/artemeter (coartem) have redox active moieties, and they interact with amino acids and other chemicals. In addition, clay montmorillonite (bentonite) and polythiophene, a conducting polymer has been used as host matrices [14-18] in the electrochemical study of metakelfin and lumefantrine/artemeter (coartem).

\section{Experiments}

Pyrimethamine/2-sulfanilamido-3-methoxypyrazine (metakelfin) and lumefantrine/artemeter (coartem) were purchased from reputable drug stores and were used as received without further purification. The biomolecules - arginine, leucine, methionine, tyrosine, acetylsalicylic acid and isonicotinic acid (all Aldrich) were used as received without further purification. The thiophene monomer (Aldrich 99\%) was triply distilled until a colorless liquid was obtained. It was then stored under nitrogen.

All solutions were prepared using de-ionized water. The clay montmorillonite, bentonite (sourced from Athi River Mining Company Ltd., Kenya) was purified as described by Refs. [19-21]. It has a mesh size ranging from $150 \mu \mathrm{m}$ to $200 \mu \mathrm{m}$, CEC (cation exchange capacity) $1.18-1.22 \mathrm{mM} / \mathrm{g}$ and a $\mathrm{pH}$ range of 8.4-9.6. The density of the bentonite is $1.25 \mathrm{~g} / \mathrm{cm}^{3}$ which are comparable to other clay minerals from different parts of the world [17]. It has a solvent retention capacity of $22.5 \%$ and $4.8 \%$ for water and organic solvents, respectively, while its moisture content is $8.5 \%$. It swells by a factor of 1.7 and 1.4 in water and organic solvents, respectively.

In generating the cyclic potential scans, two sets of instruments were used. These comprised of a PAR (Princeton Applied Research) model 173 potentiostat/galvanostat, a logarithmic current converter model 369 that controlled the current, a PAR model 175 universal programmer. The output signal was fed into a PAR RE $0089 \mathrm{X}-\mathrm{Y}$ recorder.

\section{Results and Discussion}

\subsection{Bentonite Modified Electrode}

The carbon graphite working electrode was modified using bentonite as the host matrix. The bentonite was mixed with $0.3 \mathrm{~g}$ of pyrimethamine /2-sulfanilamido-3-methoxypyrazine (metakelfin). The working electrode was then modified as described in Ref. [21]. The potential of the electrode was then cycled in a solution containing in $1 \mathrm{M} \mathrm{H}_{2} \mathrm{SO}_{4}$ solution within a potential range of $-0.4 \mathrm{~V}$ to $0.9 \mathrm{~V}$ at a scan rate of $20 \mathrm{mV} / \mathrm{s}$. The cyclic voltammetric response obtained is shown in Fig. 1.

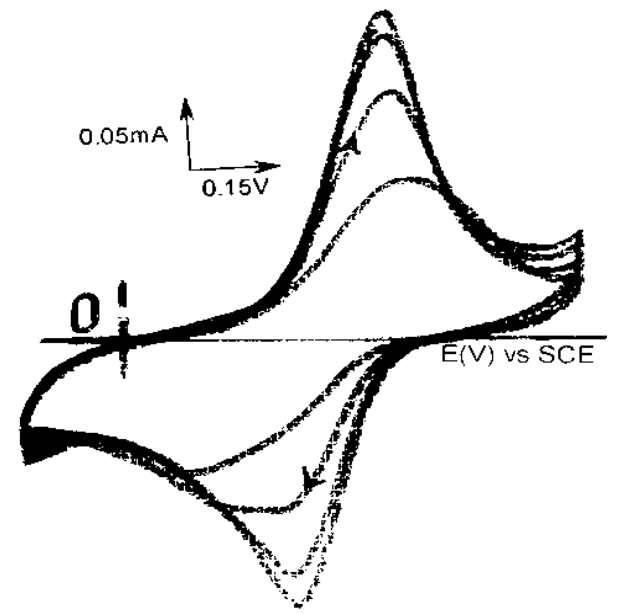

Fig. 1 Cyclic voltammogram obtained when bentonite and 2-sulfanilamido-3-methoxypyrazine/pyrimethamine modified carbon working electrode was cycled in $1 \mathrm{M} \mathrm{H}_{2} \mathrm{SO}_{4}$ : Potential range: $-0.4 \mathrm{~V}$ to $0.9 \mathrm{~V}$; Scan rate of $20 \mathrm{mV} / \mathrm{s}$. 
(Metakelfin) and LumefantrinelArtemeter (Coartem)

The oxidation peak was observed at $0.495 \mathrm{~V}$ and a reduction peak at $0.300 \mathrm{~V}$. The redox peak profile becomes sharper with increased potential cycling suggesting improvement in the Faradaic process. The electrode was then transferred to solutions having different $\mathrm{pH}$. The oxidation peak potential shifted positively with decreasing in $\mathrm{pH}$ (Fig. 2).

The change in $\mathrm{pH}$ is $56 \mathrm{mV} / \mathrm{pH}$ unit. This suggests, within the limit of experimental error, a $1 \overline{\mathrm{e}} / 1 \mathrm{H}^{+}$ process (Schemes 1 and 2).

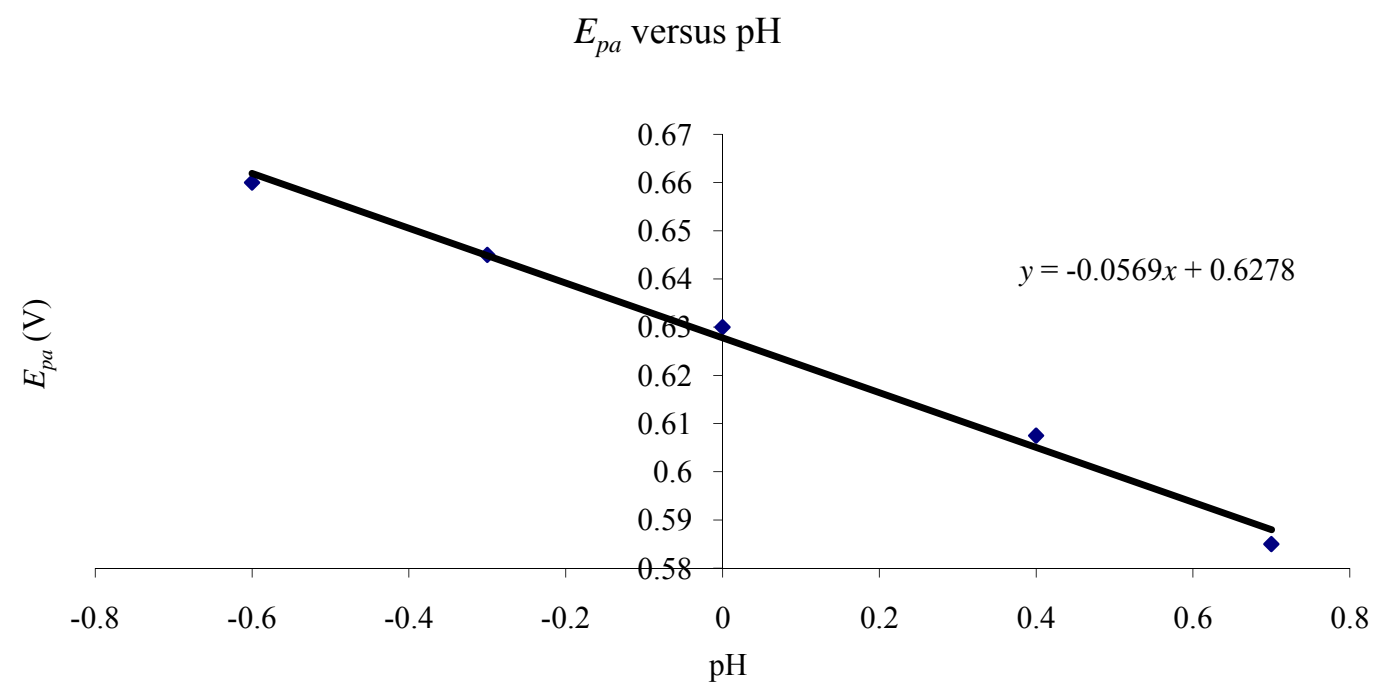

Fig. 2 Plot of $E_{p a}$ versus $\mathrm{pH}$ in the case of bentonite and 2-sulfanilamido-3-methoxypyrazine/pyrimethamine modified carbon working electrode.<smiles>CC(C)c1nc(N)nc(N)c1-c1ccc(Cl)cc1</smiles><smiles>C=C=CC(=O)c1nc(N)nc(N)c1-c1ccc(Cl)cc1</smiles><smiles>C#CC#CCCCCCO</smiles>

Scheme 1 Proposed pathway oxidation/reduction of pyrimethamine. 
<smiles>COc1ncnc2c1O[W](=O)N(S(=O)(=O)c1ccc(N)cc1)[C@H]2O</smiles><smiles>COc1ncnc(N)c1OC</smiles><smiles></smiles>

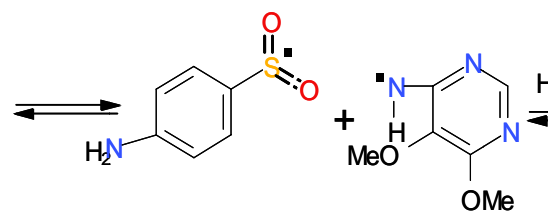<smiles>[CH]C(=O)Nc1ccc(S(=O)(=O)c2ccccc2)cc1</smiles><smiles>COc1ncnc(N)c1N(C)O</smiles><smiles>Nc1ccc(C=C[CH][OH+]S(=O)(=O)c2ccc(N)cc2)cc1</smiles><smiles>[CH]c1ncnc(OC)c1OC</smiles><smiles>COc1ncnc(N)c1OC</smiles><smiles>[In][In]</smiles><smiles>COc1ncnc(N)c1OC</smiles>

Scheme 2 Proposed pathway of oxidation/reduction of sulfadoxine.

\subsection{Bare Carbon Graphite Working Electrode}

The same process was repeated on unmodified (bare) carbon working electrode. The cyclic voltammetric response is shown in Fig. 3.

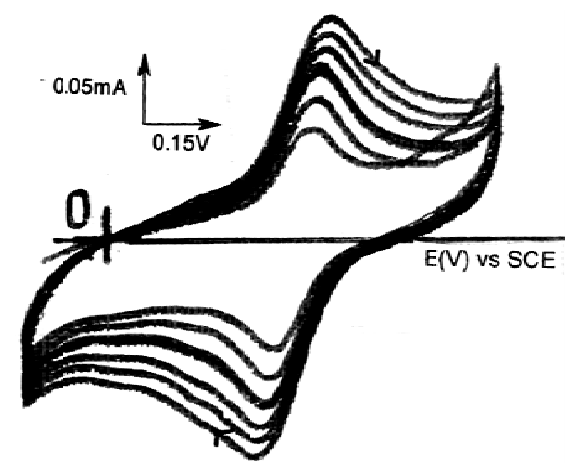

Fig. 3 Cyclic voltammogram when a bare carbon working electrode was cycled in 2-sulfanilamido-3-methoxypyrazine/pyrimethamine and 1 $\mathrm{M} \mathrm{H}_{2} \mathrm{SO}_{4}$. Potential range: $-0.4 \mathrm{~V}$ to $0.9 \mathrm{~V}$. Scan rate of 20 $\mathrm{mV} / \mathrm{s}$.
The oxidation potential is observed to occur at $0.495 \mathrm{~V}$ and the reduction potential at $0.315 \mathrm{~V}$ when the potential is cycled from $-0.4 \mathrm{~V}$ to $0.9 \mathrm{~V}$ at a scan rate of $20 \mathrm{mV} / \mathrm{s}$. Other than the small positive shift of $15 \mathrm{mV}$ in the reduction peak potential, the oxidation potential is unchanged. This suggests that, the clay montmorillonite host matrix did not significantly alter its redox potential. This is not surprising given the size of the molecules involved, hence isomorphous exchange/substitution with the tetrahedral and octahedral sites in bentonite is not possible.

\subsection{Metakelfin Modified Electrode}

Metakelfin was used as the electrode surface modification material. The electrode potential was cycled from $-0.2 \mathrm{~V}$ to $0.9 \mathrm{~V}$ at a scan rate of $20 \mathrm{mV} / \mathrm{s}$ in $1 \mathrm{M} \mathrm{H}_{2} \mathrm{SO}_{4}$. The resultant cyclic voltammetric 

(Metakelfin) and Lumefantrine/Artemeter (Coartem)

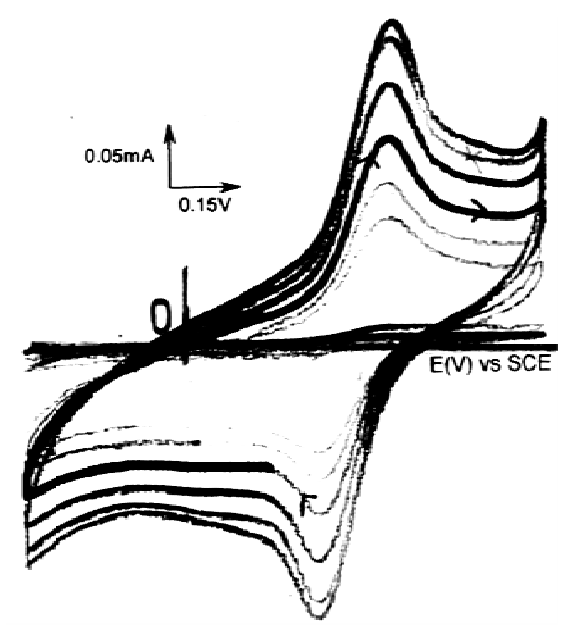

Fig. 4 Cyclic voltammogram when 2-sulfanilamido-3-methoxy pyrazine/pyrimethamine modified carbon working electrode was cycled in $1 \mathrm{M}$ $\mathrm{H}_{2} \mathrm{SO}_{4}$. Potential range: $-0.2 \mathrm{~V}$ to $0.9 \mathrm{~V}$. Scan rate of 20 $\mathrm{mV} / \mathrm{s}$.

response is shown in Fig. 4.

We observe the oxidation potential at $0.510 \mathrm{~V}$ and reduction potential at $0.315 \mathrm{~V}$.

The redox potential does not change significantly.

Calculation of the surface coverage yielded a value of $1.09 \times 10^{-9} \mathrm{~mol} / \mathrm{cm}^{2}$ as compared to an actual value of $8.02 \times 10^{-6} \mathrm{~mol} / \mathrm{cm}^{2}$. This suggests that the percentage of the electroactive species is $0.136 \%$.

\subsection{Polythiophene Modified Electrode}

Polythiophene modified electrode was prepared as described in Ref. [16]. The choice of polythiophene was anchored on the fact that, thiophene monomer, the building block in polythiophene is a sulfur containing heterocyclic. The polythiophene electrode was the transferred to a solution containing 3,000 ppm pyrimethamine/2-sulfanilamido-3-methoxypyrazine in $1 \mathrm{M} \mathrm{H}_{2} \mathrm{SO}_{4}$ and the potential cycled from $-0.4 \mathrm{~V}$ to 0.9 $\mathrm{V}$ at a scan rate of $20 \mathrm{mV} / \mathrm{s}$.

The resultant cyclic voltammogram does not show distinct peaks for polythiophene and pyrimethamine/2-sulfanilamido-3-methoxypyrazine.

There appears to be an overlap in the redox centres. There is a very slight negative shift in the oxidation and reduction potentials. These slight shifts in potential do not convey any significant information relating to the behavior of pyrimethamine/2-sulfanilamido-3-methoxypyrazine on the electrode (Fig. 5b).

\subsection{Interactions of Metakelfin with Other Chemicals}

The redox properties of pyrimethamine/2-

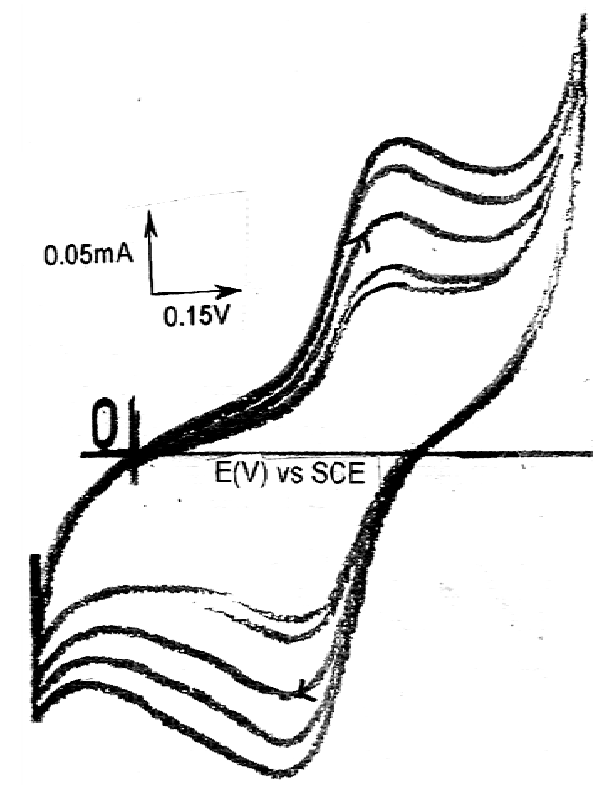

(a)

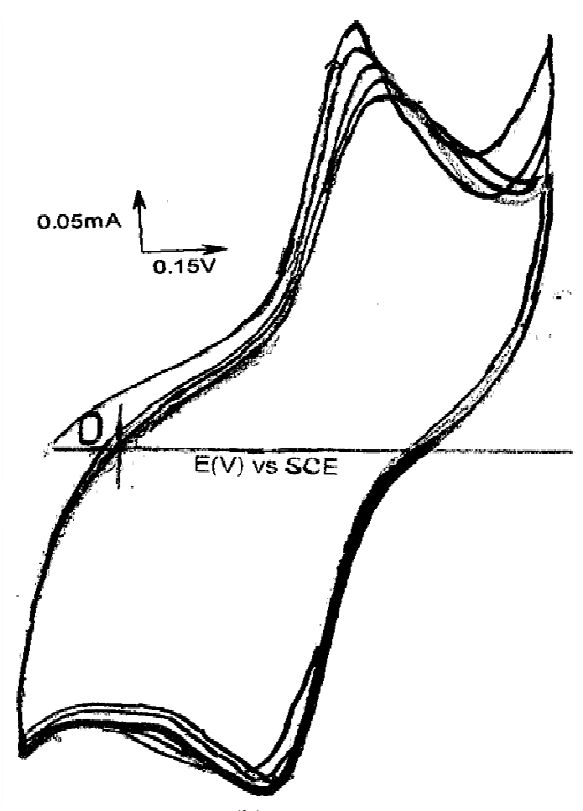

(b)

Fig. 5 Cyclic voltammogram when polythiophene modified carbon working electrode (a) was cycled in solution containing 3,000 ppm pyrimethamine/2-sulfanilamido-3-methoxypyrazine in $1 \mathrm{M} \mathrm{H}_{2} \mathrm{SO}_{4}$. Potential range: $-0.2 \mathrm{~V}$ to $0.9 \mathrm{~V}$. Scan rate of 20 $\mathrm{mV} / \mathrm{s}$. 


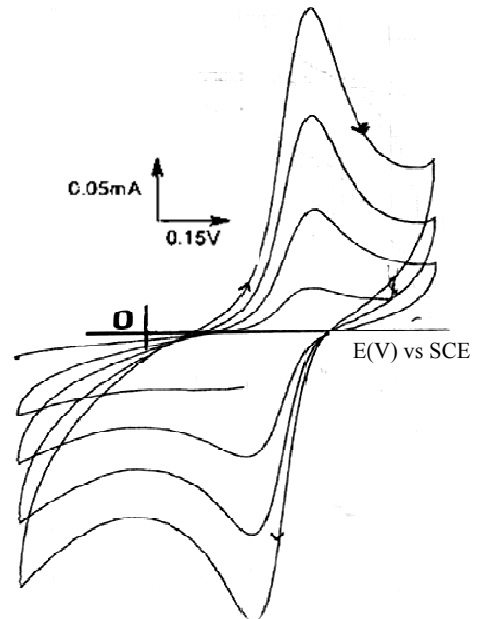

(a)

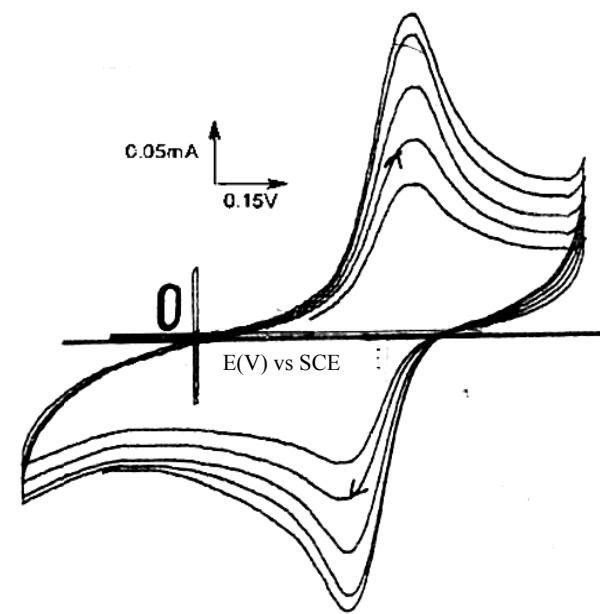

(b)

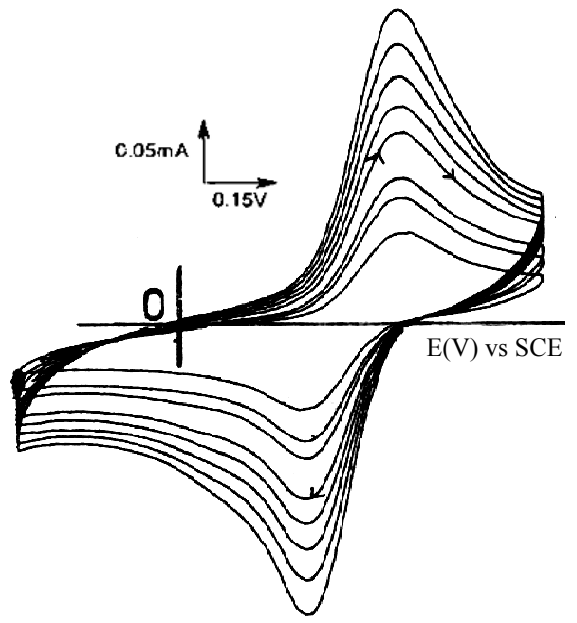

(c)

Fig. 6 (a) Cyclic voltammogram of 2-sulfanilamido-3methoxy pyrazine/pyrimethaminemodified electrode in arginine in $1 \mathrm{M}$ $\mathrm{H}_{2} \mathrm{SO}_{4}$. Potential range: $-0.2 \mathrm{~V}$ to $0.9 \mathrm{~V}$. Scan rate of $20 \mathrm{mV} / \mathrm{s}$. (b) Cyclic voltammogram of 2-sulfanilamido-3methoxy pyrazine/pyrimethaminemodified electrode in leucine in $1 \mathrm{M} \mathrm{H}_{2} \mathrm{SO}_{4}$. Potential range: $-0.2 \mathrm{~V}$ to $0.9 \mathrm{~V}$. Scan rate of $20 \mathrm{mV} / \mathrm{s}$. (c) Cyclic voltammogram of 2-sulfanilamido-3methoxy pyrazine/pyrimethaminemodified electrode in tri-sodium citrate in $1 \mathrm{M}$ $\mathrm{H}_{2} \mathrm{SO}_{4}$. Potential range: $-0.2 \mathrm{~V}$ to $0.9 \mathrm{~V}$. Scan rate of $20 \mathrm{mV} / \mathrm{s}$.

sulfanilamide-3-methoxypyrazine, when used as a modification material but in a solution containing $1 \mathrm{M}$ $\mathrm{H}_{2} \mathrm{SO}_{4}$ and 4,000 ppm arginine, leucine and tri-sodium citrate. In all the cases, there was a significant improvement in the reversibility of the redox process (Fig. 6). The redox peaks were much sharper with a peak tailing, typical of a diffusion limited process.

Similar improvements were noted with isonicotinic acid and acetylsalicylic acid (Figs. 7 and 8). The improvements in redox process is probably the result of complimentary interaction between the redox centres or electro-catalytic role of one of the chemical species.

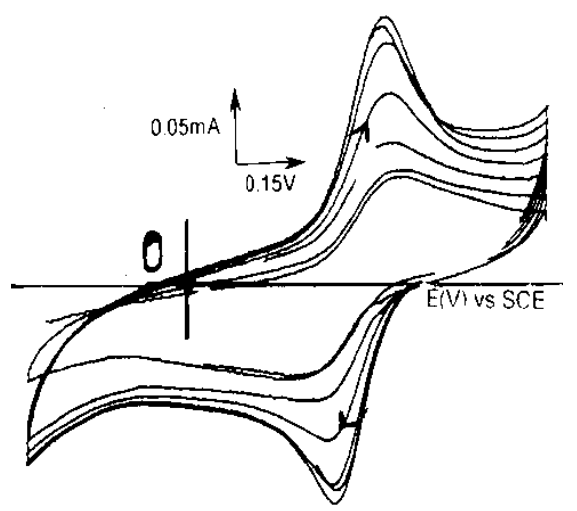

Fig. 7 Cyclic

voltammogram

when 2-sulfanilamido-3methoxy pyrazine/pyrimethamine and isonicotinic acid modified carbon working electrode was cycled in $1 \mathrm{M} \mathrm{H}_{2} \mathrm{SO}_{4}$. Potential range: $-0.2 \mathrm{~V}$ to $0.9 \mathrm{~V}$. Scan rate of $20 \mathrm{mV} / \mathrm{s}$.

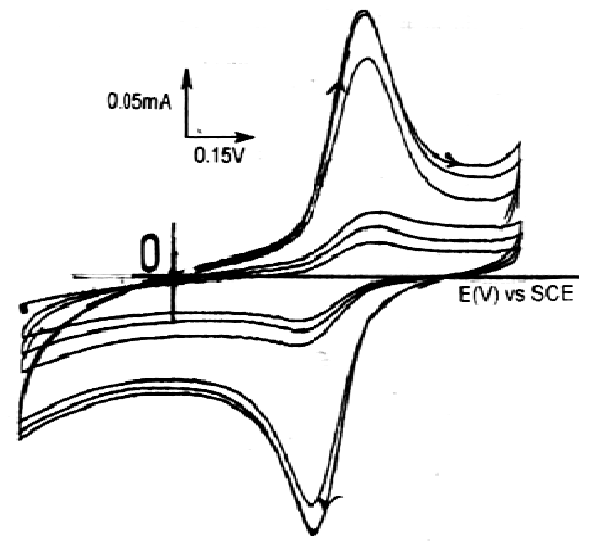

Fig. 8 Cyclic voltammogram when 2-sulfanilamido-3-methoxy pyrazine/pyrimethamine and acetylsalicylic acid modified carbon working electrode was cycled in $1 \mathrm{M} \mathrm{H}_{2} \mathrm{SO}_{4}$. Potential range: $-0.2 \mathrm{~V}$ to $0.9 \mathrm{~V}$. Scan rate of $20 \mathrm{mV} / \mathrm{s}$.

Thus, from the cyclic voltammetric responses, it is apparent that the aminoacids and other compounds discussed in the foregoing paragraph affect the redox behavior of pyrimethamine/2-sulfanilamido-3-methoxy pyrazine. It is therefore possible that, if these effects are mirrored at the physiological level in living beings, then patients using metakelfin as a prescription drug to fight malaria should be alerted of these interactions. These interactions can alter the efficacy of the drug significantly i.e., a patient in contact with these substances through addiction to smoking therefore, 
high level of nicotine in the blood or use of aspirin as medication in the case of heart ailment or as analgesic.

\subsection{Lumefantrine/Artemer-Coartem}

\subsubsection{Bare Carbon Graphite Working Electrode}

Electro-analysis was done on coartem, where 120 $\mathrm{mg}$ of lumefantrine and $20 \mathrm{mg}$ artemeter were dissolved in $1 \mathrm{M} \mathrm{H}_{2} \mathrm{SO}_{4}$ solution and the potential cycled from $-0.4 \mathrm{~V}$ to $0.9 \mathrm{~V}$. Scan rate was $20 \mathrm{mV} / \mathrm{s}$. The resultant cyclic voltammogram had well defined oxidation and reduction peaks. The oxidation peak occurred at $0.510 \mathrm{~V}$ and the reduction peak at $0.300 \mathrm{~V}$. The process is quasi reversible (Fig. 9).

The scan rate dependence study yielded a linear plot for peak current versus $v^{1 / 2}$ (Fig. 10). This is not surprising in that the cyclic voltammogram was characterized by peak tailing, typical of diffusion limited processes.

With each increment in peak current during oxidation/reduction, the oxidation potential shifted positively while the reduction potential shifted negatively. This suggested that the Gibbs free energy is reduced with continued cycling during the oxidation process while the reverse is true for the reduction process. This asymmetry in the Gibbs free energy behavior of oxidation and reduction process in coartem is probably attributed to discordant changes in entropy associated with the redox process. The

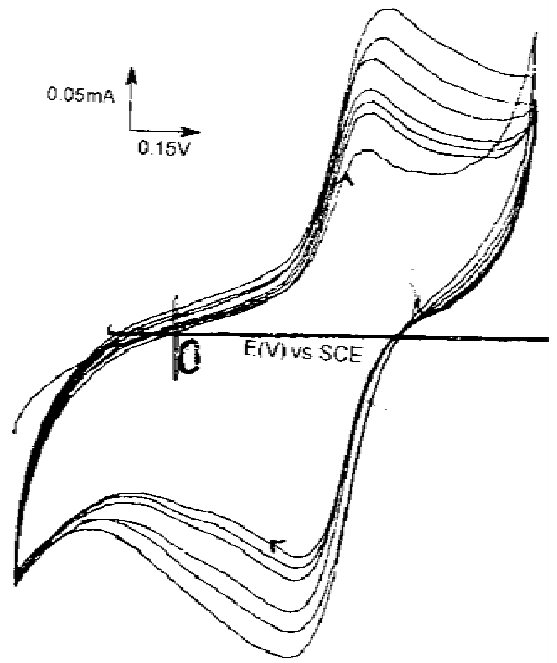

Fig. 9 Cyclic voltammetric response when bare carbon electrode was cycled in $120 \mathrm{mg}$ of lumefantrine and $20 \mathrm{mg}$ artemeter and $1 \mathrm{M} \mathrm{H}_{2} \mathrm{SO}_{4}$. Potential range: $-0.4 \mathrm{~V}$ to $0.9 \mathrm{~V}$. Scan rate of $20 \mathrm{mV} / \mathrm{s}$.

chemical structures of lumefantrine and artemetisinins are shown.

The chemical structure of artemisinin suggest it does not undergo oxidation. This assessment is supported by the fact that despite the solution being a mixture of thermodynamically stable chemical species, that is lumefantrine and artemeter, the authors obtain a single oxidation peak attributable to lumefantrine. When the $\mathrm{pH}$ of the electrolyte solution was varied, the variation in $E_{p}$ with solution $\mathrm{pH}$ was $72 \mathrm{mV} / \mathrm{pH}$ unit. suggesting that the redox process is not a $1 \overline{\mathrm{e}} / 1 \mathrm{H}^{+}$process (Fig. 12).

$$
i_{p a} \text { versus } v^{1 / 2}
$$

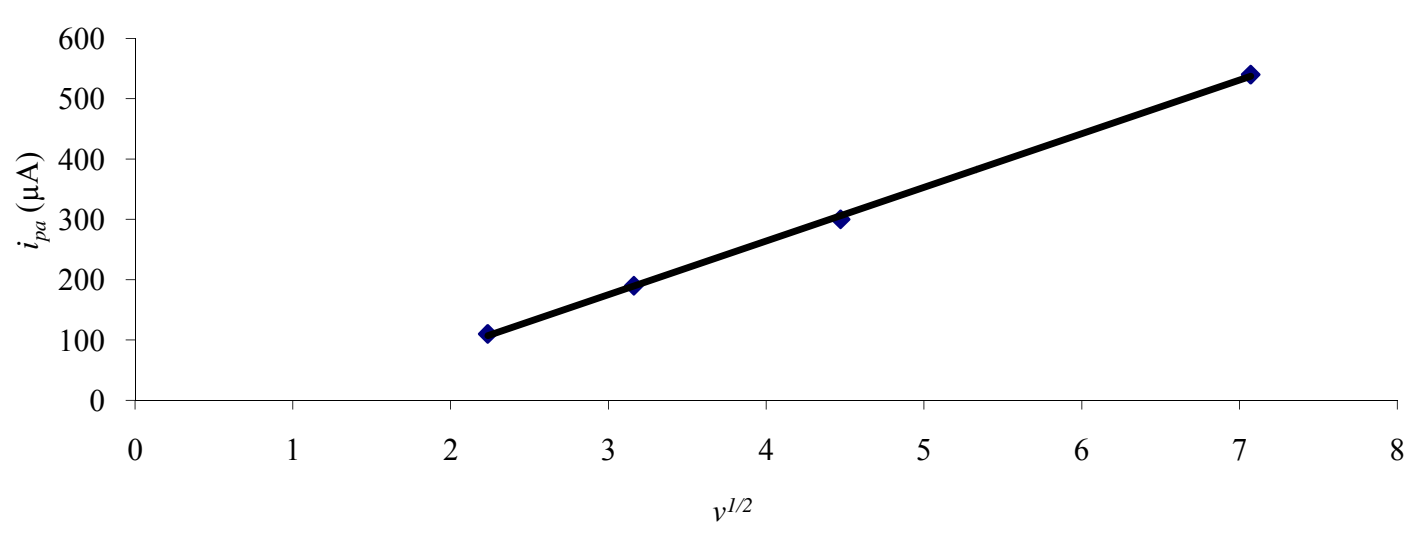

Fig. 10 Plot of $i_{p a}$ versus $v^{1 / 2}$ for coartem on bare carbon electrode. 
<smiles>[R2]C1([R1])OC2OC3(C)CCC4C(C)CCC5OOC2(C1C5C)C43</smiles>

Artemisinins

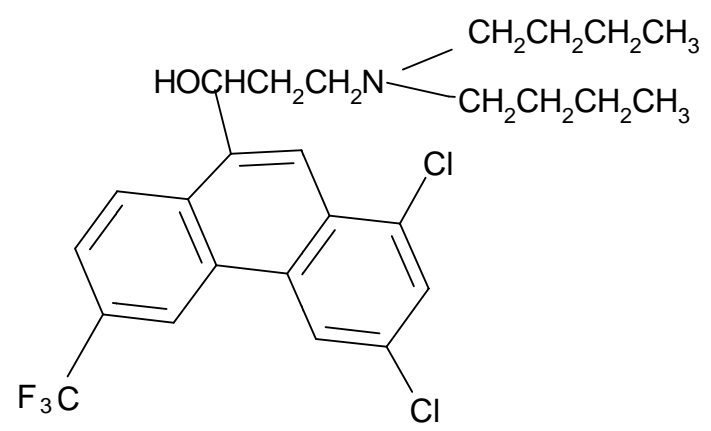

Fig. 11 Lumefantrine.

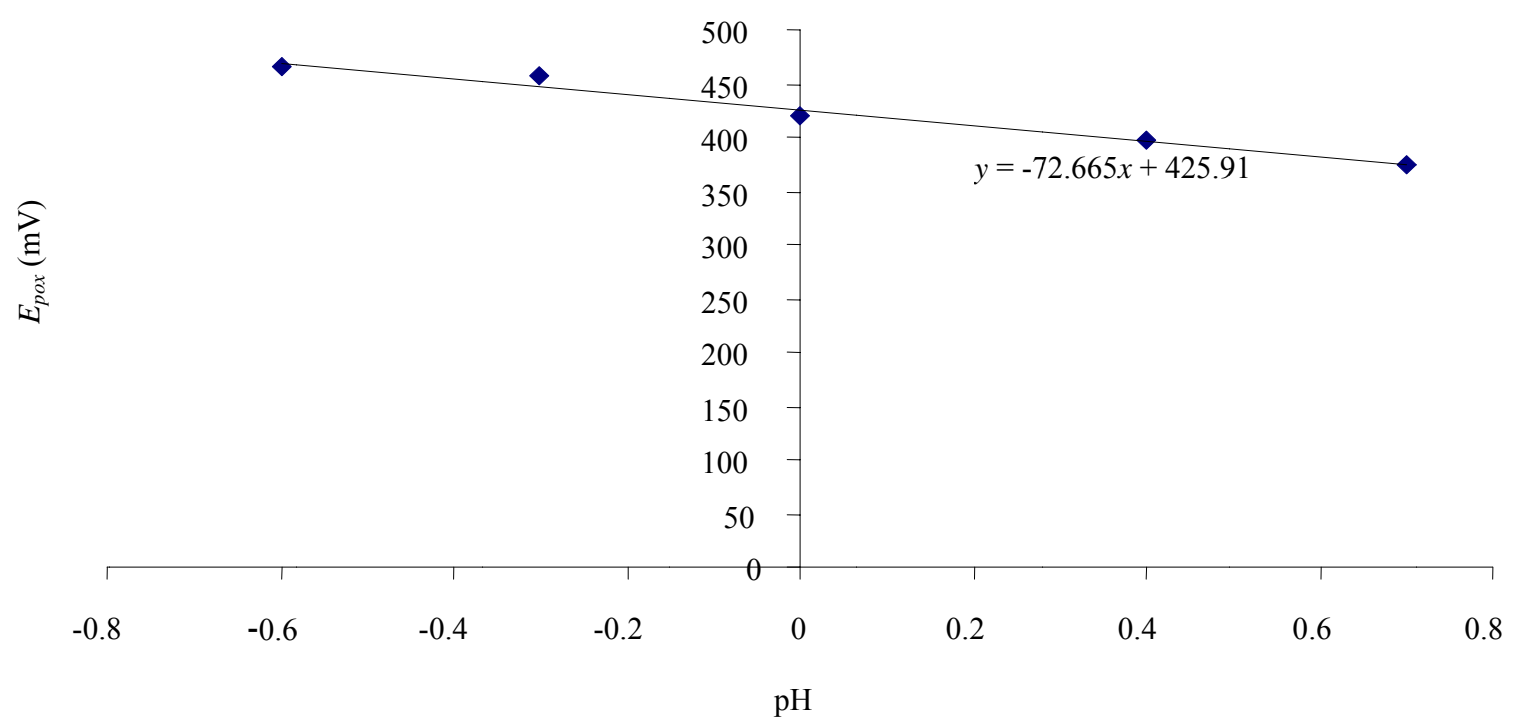

Fig. 12 Plot of $E_{p o x}$ versus solution $\mathrm{pH}$ for coartem on bare carbon electrode.

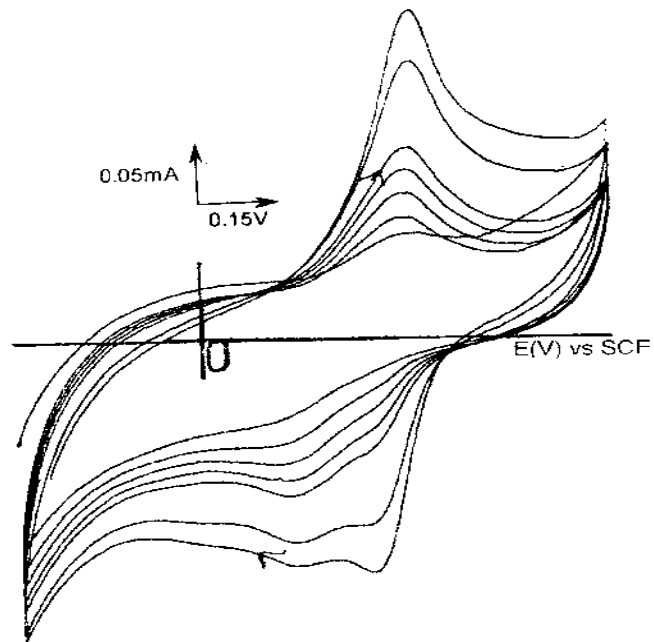

Fig. 13 Cyclic voltammogram obtained when bentonite modified working electrode was cycled in $120 \mathrm{mg}$ of lumefantrine and $20 \mathrm{mg}$ artemeter and $1 \mathrm{M} \mathrm{H}_{2} \mathrm{SO}_{4}$. Potential range: $-0.4 \mathrm{~V}$ to $0.9 \mathrm{~V}$. Scan rate of $20 \mathrm{mV} / \mathrm{s}$.

\subsubsection{Bentonite Modified Working Electrode}

The same mixture was then analyzed on a bentonite modified working electrode and the resultant cyclic voltammogram is shown in Fig. 13.

The oxidation peak occured at $0.450 \mathrm{~V}$ while a double humped reduction peak, occured at $0.180 \mathrm{~V}$ and $0.225 \mathrm{~V}$. The peak tailing is still observable suggesting that it is still a diffusion limited process. The double humped reduction peak is probably resulting from a chemical reaction (e-c mechanism). Lumefantrine chemical structure will most likely be sterically hindered from accessing the octahedral $\left(O_{h}\right)$ and tetrahedral sites $\left(T_{d}\right)$ in the bentonite. But, this does not limit or inhibit complimentary interaction between their redox spheres. The metal 

(Metakelfin) and Lumefantrine/Artemeter (Coartem)

ions, i.e., $\mathrm{Ca}^{2+}, \mathrm{Mg}^{2+}$ in the $\mathrm{O}_{h}$ sites are redox active and can catalyze or inhibit the redox process. In this particular case the oxidation occurs at lower potential, probably a veiled pointer to electro-catalysis.

\subsection{Interaction of Coartem with Amino-Acids}

The electrochemical effect of biochemical substances such as methionine, arginine, tyrosine and leucine on

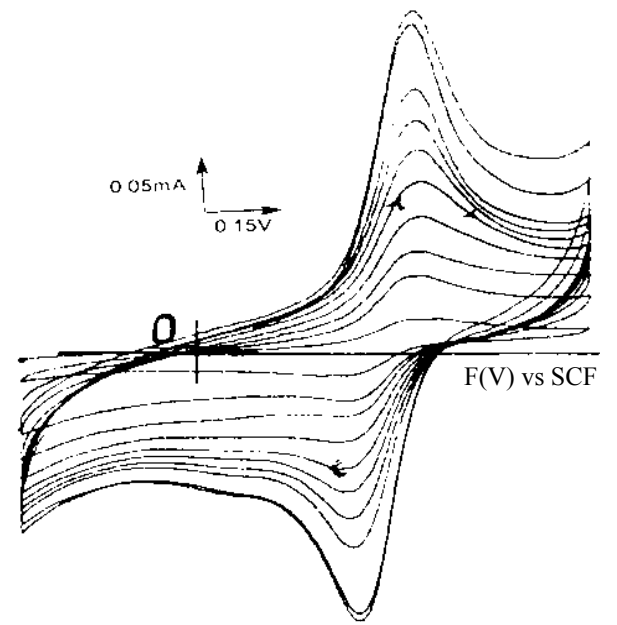

(a)

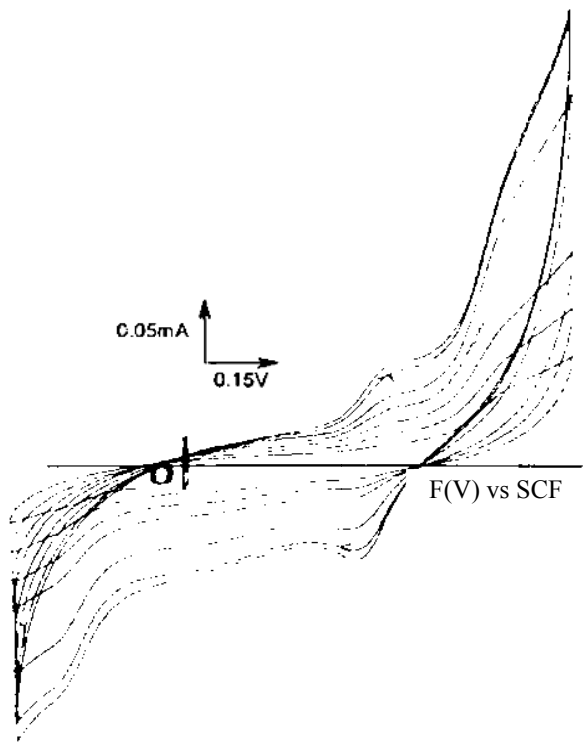

(c) lumefantrine/artemeter are shown in Fig. 14. The lumefantrine/artemeter modified electrode was cycled in a solution containing 4,000 ppm of the aminoacid in a solution containing $1 \mathrm{M} \mathrm{H}_{2} \mathrm{SO}_{4}$. The potential was cycled from $-0.4 \mathrm{~V}$ to $0.9 \mathrm{~V}$, at a scan rate of $20 \mathrm{mV} / \mathrm{s}$.

In the methionine case, there is no shift in oxidation potential with the continued potential cycling. In the case of arginine, it is also observed that with the

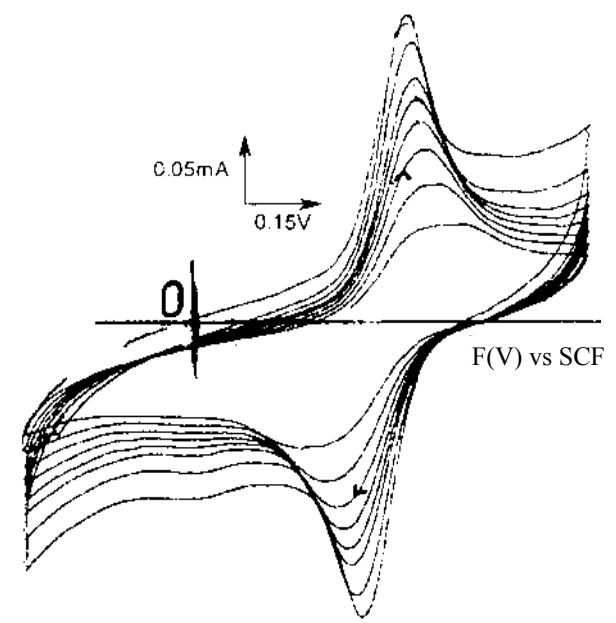

(b)

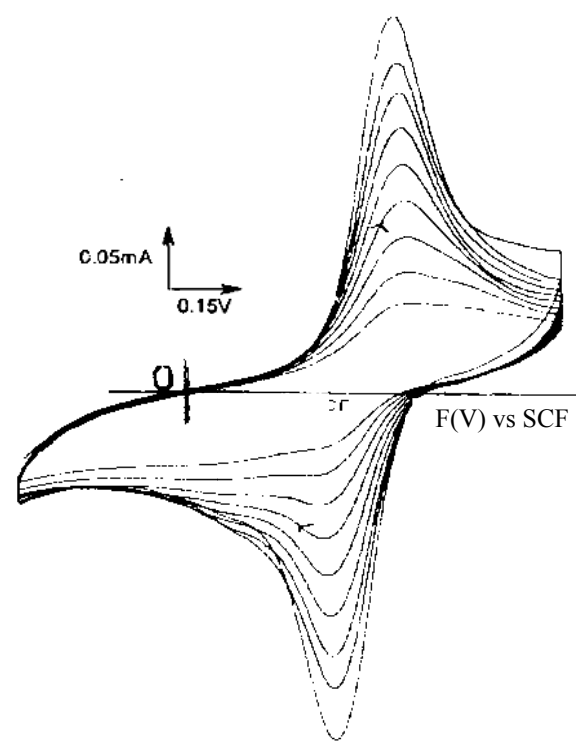

(d)

Fig. 14 (a) Cyclic voltammogram obtained when lumefantrine/artemeter modified working electrode was cycled of 4,000 ppm methionine in $1 \mathrm{M} \mathrm{H}_{2} \mathrm{SO}_{4}$. Potential range: $-0.4 \mathrm{~V}$ to $0.9 \mathrm{~V}$. Scan rate of $20 \mathrm{mV} / \mathrm{s}$. (b) Cyclic voltammogram obtained when lumefantrine/artemeter modified working electrode was cycled of 4,000 ppm arginine in $1 \mathrm{M} \mathrm{H}_{2} \mathrm{SO}_{4}$. Potential range: $-0.4 \mathrm{~V}$ to $0.9 \mathrm{~V}$. Scan rate of $20 \mathrm{mV} / \mathrm{s}$. (c) Cyclic voltammogram obtained when lumefantrine/artemeter modified working electrode was cycled in 4,000 ppm tyrosine in $1 \mathrm{M} \mathrm{H}_{2} \mathrm{SO}_{4}$. Potential range: $-0.4 \mathrm{~V}$ to $0.9 \mathrm{~V}$. Scan rate of $20 \mathrm{mV} / \mathrm{s}$. (d) Cyclic voltammogram obtained when lumefantrine/artemeter modified working electrode was cycled in 4,000 ppm leucine in $1 \mathrm{M}$ $\mathrm{H}_{2} \mathrm{SO}_{4}$. Potential range: $-0.4 \mathrm{~V}$ to $0.9 \mathrm{~V}$. Scan rate of $20 \mathrm{mV} / \mathrm{s}$. 

(Metakelfin) and LumefantrinelArtemeter (Coartem)

increment in peak current, the oxidation potential shifts negatively while the reduction potential shifts positively. This is attributed to the asymmetry in the free energy dynamics as already discussed

In the case of tyrosine, the broad and mishapened peaks obtained suggest an inefficient redox process. This suggests that tyrosine suppresses/inhibits the redox activity of lumefantrine. This can have serious consequences vis à vis the drug (lumefantrine) action in a system where there are traces of tyrosine. This is especially so if we assume that the therapeutic activities of lumefantrine and artemeter at the physiological level are redox based.

Leucine, another amino acid yielded very sharp and reversible peaks (Fig. 14d). This improvement in the Faradaic process is probably the result of interaction between the two redox centres.

\section{Conclusions}

It is apparent from the results presented that pyrimethamine/2-sulfanilamido-3-methoxypyrazine (metakelfin) and lumefantrine/artemeter (coartem) have redox active moieties. When the working electrode surface is chemically modified using these drugs ample electrochemical information is obtained from cyclic voltammetry. It is also observed that, these drugs interact electrochemically with amino acids. It is therefore necessary to continue with in-depth studies to establish whether these interactions are replicated at the physiological/biochemical levels in living beings.

\section{References}

[1] Parafitt, K. Antimalarials. In Martindale: The Complete Drug Reference; 1999; pp 422-442.

[2] Avery, M. A.; Mehrotra, S.; Bonk, J. D.; Vroman, J. A.; Goins, D. K.; Miller, R. Structure-Activity Relationships of the Antimalarial Agent Artemisinin Effect of Substitution at C-3. J. Med. Chem. 1996, 39, 2900-2906.

[3] Acton, N.; Roth, R. J. On the Conversion of Dihydroartemisinic Acid into Artemisinin. J. Org. Chem. 1992, 57, 3610-3614.

[4] Adriana, M.; Erika, S.; Domenica, T. Electrodeposited
Glucose Oxidase/Anionic Clay for Glucose Biosensors Design. Analytica Chimica Acta 2006, 577, 98-106.

[5] Bachi, M. D.; Korshin, E. E.; Hoos, R.; Szpilman, A. M. Synthesis and Reactions of Antimalarial Bicyclic Peroxides. J. Heterocycl. Chem. 2000, 37, 639-646.

[6] Bakhshi, H. B.; Gordi, T.; Ashton, M. In-vitro Interaction of Artemisinin with Intact Human Erythrocytes, Erythrocyte Ghosts, Haemoglobin and Carbonic Anhydrase. J. Pharm. Pharmacol. 1997, 49, 223-226.

[7] Benoit-Vical, F.; Robert, A.; Meunier, B. In Vitro and in Vivo Potentiation of Artemisinin and Synthetic Endoperoxyde Antimalarial Drugs by Metalloporphyrins. Antimicrob. Agents Chemother. 2000, 44, 2836-2841.

[8] Berman, P. A.; Adams, P. A. Artemisinin Enhances Heme-Catalysed Oxidation of Lipid Membranes. Free Radic. Biol. Med. 1997, 22, 1283-1288.

[9] Bharel, S.; Vishwakarma, R. A.; Jain, S. K. Artemisinin Mediated Alteration of Haemin to a Delta-Meso Oxidation Product: Relevance to Mechanism of Action. $J$. Chem. Soc. Perkin. Trans. I 1998, 1, 2163-2166.

[10] Bunnag, D.; Kanda, T.; Karbwang, J.; Thimasarn, K.; Pungpak, S.; Harinasuta, T. Artemether-Mefloquine Combination in Multidrug Resistant Falciparum Malaria. Trans. R. Soc. Trop. Med. Hyg. 1995, 89, 213-215.

[11] Chandrasekharan, N. V.; Dai, H.; Roos, K. L., COX-3, A Cyclooxygenase-1 Variant Inhibited by Acetaminophen and Other Analgesic/Antipyretic Drugs: Cloning, Structure and Expression. Proc. Natl. Acad. Sci. U.S.A. 2002, 99, 13926-31.

[12] Cumming, J. N.; Ploypradith, P.; Posner, G. H. Antimalarial Activity of Artemisinin (Qingh aosu) and Related Trioxanes: Mechanism(s) of Action. Advances in Pharmacology (San Diego) 1997, 37, 253.

[13] Downard, A. J.; Pletcher, D. A Study of the Conditions for the Electrodeposition of Polythiophene in Acetronitrile. J. Electroanal. Chem. 1986, 206, 147-152.

[14] Ege, D.; Gosh, P. K.; White, J. R.; Equey, J. F.; Bard, A. J. Clay Modified Electrodes 3: Electrochemical and Electron Spin Resonance Studies of Montmorillonite Layers. J. Am. Chem. Soc. 1984, 107, 5644-5646.

[15] Elliot, C. M.; Murray, R. W. Chemically Modified Carbon Electrodes. Anal. Chem. 1976, 48, 1247.

[16] Evans, J. F.; Kuwana, T.; Henne, M. T.; Royer, J. P. Electrocatalysis of Solution Species Using Modified Electrodes. J. Electroanal. Chem. Soc. 1977, 80, 409-416.

[17] Firth, B. E.; Murray, R. W.; Miller L. L.; Mitani, M.; Rogers, T.; Lennox, J. Anodic and Cathodic Reactions on a Chemically Modified Edge Surface of Graphite. J. Am. Chem. Soc. 1976, 98, 8271-8274.

[18] Firth, B. E.; Murray, R. W.; Miller, L. L.; Mitani, M.; Rogers, T.; Lennox, J. Anodic and Cathodic Reactions on a Chemically Modified Edge Surface of Graphite. J. Am. 

(Metakelfin) and LumefantrinelArtemeter (Coartem)

Chem. Soc. 1976, 98, 8271-8274.

[19] Ege, D.; Gosh, P. K.; White, J. R.; Equey, J. F.; Bard, A. J. Clay Modified Electrodes 3: Electrochemical and Electron Spin Resonance Studies of Montmorillonite Layers. J. Am. Chem. Soc. 1984, 107, 5644-5646.
[20] Gosh, P. K.; Bard, A. J. Clay Modified Electrodes Part II. J. Electroanal. Chem. Soc. 1983, 105, 5691-5693.

[21] Orata, D. O.; Segor, F. Bentonite as a Template for Electro-Synthesis of Thyroxine. Catalysis Letter 1999, 58, 157-163. 